\title{
La construcción de la cosmovisión durante la enseñanza
}

\section{Romano, Ana María}

Resumen: La enseñanza del diseño, por las propias características de su hacer, suele mantener tácitas las argumentaciones que la fundamentan, no obstante, durante la formación las mismas van construyendo en los alumnos la mirada sobre la disciplina.

Este proceso, que se realiza en un marco institucional, es planificado por las cátedras que dictan la materia bajo la propuesta pedagógica de cada uno de los profesores titulares, la que será finalmente interpretada e implementada por los docentes de su equipo, en vínculo directo con los estudiantes.

Los alumnos, por su parte, llegan con sus historias de vida y su bagaje de concepciones previamente adquiridos en su contexto familiar, social y su formación previa, a partir de las cuales

Cuadernos del Centro de Estudios de Diseño y Comunicación Nº 67

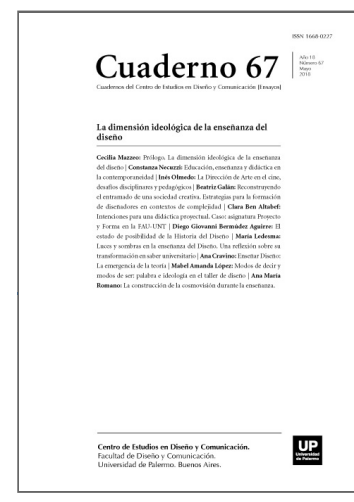

ISSN: 1668-0227

La dimensión

ideológica de la

enseñanza del diseño

Año XVIII, Mayo 2018, Buenos Aires, Argentina | 260 páginas

descargar PDF

ver índice de la publicación

Ver todos los libros de la publicación

compartir en Facebook

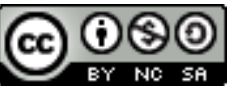

Esta obra está bajo una Licencia Creative Commons Atribución-NoComercialCompartirlgual 4.0 Internacional van a incorporar los nuevos conocimientos, modificando esas estructuras preexistentes.

La diversidad de propuestas y protagonistas que confluyen en el marco de la enseñanza invitan a reflexionar sobre las distintas instancias que van dando forma a esas concepciones de los estudiantes durante el aprendizaje de diseño y que construyen su futuro perfil profesional y su cosmovisión, en tanto en el ejercicio profesional esas concepciones van a ser transferidas a los objetos diseñados, influyendo directamente sobre los usuarios y el hábitat con el cual interactúan.

La posibilidad de transparentar este proceso en cada una de las cátedras podría permitir el análisis crítico y la revisión de los objetivos y de las prácticas planteados y evaluar las consecuencias una vez implementados, a los efectos de mejorar la enseñanza, ampliar el conocimiento de la realidad y aumentar el compromiso social.

Palabras clave: Enseñanza - Aprendizaje - Cosmovisión - Pensamiento proyectual - Diseño. 
El pensamiento pragmático que caracteriza a las disciplinas de diseño, incluida la arquitectura, suele extenderse a su modalidad de enseñanza y, al programar su implementación, no siempre se explicitan conscientemente los criterios con los que se realiza el recorte de las variables consideradas y este enfoque holístico suele ocultar los fundamentos de tales elecciones, pasando por alto que para los estudiantes "el trabajo que se desarrolla en los talleres de diseño excede la sola práctica proyectual para constituirse en introductorio a las particularidades del campo mismo". (Mazzeo, 2014, p. 43)

Bajo el mismo cono de sombra suele quedar velada la dimensión ideológica de estas propuestas que, no obstante, dejan su impronta en la formación y el futuro ejercicio profesional. Tal vez sea oportuno, entonces, recorrer los distintos momentos, durante el proceso de enseñanza, en que este perfil ideológico se va construyendo, comprender sus orígenes, sus implicancias y sus consecuencias.

Hay, efectivamente, una política de la mirada, cuya historia alguien debería alguna vez escribir: ella mostraría que, así como no hay lecturas inocentes (decía Althusser) tampoco hay formas de la mirada, que puedan pretender no sé que ingenuidad incontaminada por el barro y la sangre de la historia. (Grüner, 2002 p. 13)

El autor sostiene que "para situarse, sartreanamente, ante un mundo que aspira a una abyecta transparencia visual, es necesario empezar por confesar de qué maneras de mirar somos culpables" (Ibídem) y, agrega refiriéndose a la imagen pictórica, si bien sus alcances pueden proyectarse a otros órdenes de la visualidadque la imagen ha sido históricamente constitutiva de la subjetividad colectiva y el imaginario social histórico, con el papel constructor de la memoria que busca fijar por la mirada el orden de pertenencia para los sujetos de una cultura y, en una aparente singularidad, termina sacrificándose a la trascendencia de la idea dominante que, paradojalmente, queda oculta. (Ibídem. p. 18) A los efectos de comprender la enseñanza del diseño en su dimensión ideológica, en tanto orientadora del enfoque que recae sobre la producción de sus objetos, es conveniente mencionar las influencias que atraviesa y las múltiples interrelaciones que inciden en cada una de las secuencias decisionales, interrelaciones más o menos directas, conscientes o inconscientes, que emergen en los sucesivos órdenes de la planificación, en sus distintos niveles de generalidad y que resultan siempre sesgadas por cosmovisiones personales y sociales.

Podríamos visualizar este sistema de sucesivas y múltiples inclusiones como un conjunto de muñequitas rusas auto-contenidas en sucesión casi infinita aunque, en nuestro caso, los vínculos no son lineales sino complejos y heterogéneos.

Supera los alcances de esta reflexión analizar el contexto de la globalización, la figura envolvente mayor de la serie mencionada, caracterizada por la presión de la economía de mercado y sus influencias en todas las dimensiones sociales, con las sucesivas dependencias sobre los distintos ámbitos de la cultura. No obstante, no puede dejar de mencionarse que esta será la matriz dentro de cuyos límites estarán todas las áreas sobre las cuales fijemos nuestra atención en adelante y, por consiguiente, cualquier análisis sobre la ense- ñanza contemplará solapadamente esta omnipresencia.

Estas tensiones que actúan sobre el campo de la educación tienden a saturarlo, alterando su sentido más auténtico y muchas veces disminuyendo la presencia de los contenidos humanistas, verdaderos formadores de 
la conciencia y sensibilidad social.

La filósofa estadounidense Martha Nussbaum -Premio Príncipe de Asturias de Ciencias Sociales 2012- advertía en ocasión de recibir su doctorado honoris causa en la Universidad de Antioquía, sobre las consecuencias nefastas de una formación que deja de lado el pensamiento crítico propio de las humanidades y de las artes, para acentuar una educación basada en el PBI, que descarta las habilidades que son relevantes, tanto por sus propios aportes como para mantener vivas las democracias y el desarrollo humano genuino, en tanto la sensibilidad cultivada es enemiga de la torpeza moral necesaria para implementar programas que ignoran la desigualdad en lugar de refinar la capacidad de pensar y respetar al otro. (Nussbaum, 2015)

En nuestro país, la crisis ya endémica del sistema educativo, en todos sus niveles, y los constantes e improvisados cambios en los planes de estudio, no parecen orientarse hacia derroteros distintos de los señalados.

Cada esfera de decisión, comenzando por la política educativa nacional hasta las determinaciones que tomemos en el aula, pasando por todas las instancias intermedias, nos exigirá el posicionamiento ideológico y, en el área de diseño, la lucidez que garantice la coherencia interna y una conducta ética en todas las decisiones, considerando que las mismas recaerán sobre los usuarios y la construcción del hábitat humano.

Dentro del panorama general de la cultura debemos incluir los cambios epistemológicos producidos a partir de la crisis de la modernidad, que se gestó a finales del siglo XIX y estalló a lo largo del siglo XX, desde las Ciencias Cognitivas a las Ciencias de la Complejidad y que permite trazar una vasta cartografía que da cuenta de las líneas de descomposición de la concepción moderna del conocimiento como representación objetiva del mundo exterior en la mente del sujeto.

Enfoques, numerosos y diversos, han dado lugar a importantes desarrollos que toman en cuenta las dinámicas transformadoras de un pensamiento en permanente configuración y reconfiguración. (Najmanovich, 2010)

Esta sucesión de cambios, las nuevas formas de pensamiento, la constante renovación tecnológica y el perfil de un nuevo estudiante, abren la insoslayable perspectiva de revisión sobre nuestras propias concepciones y prácticas, obligándonos a reconsiderar objetivos, contenidos y métodos en un claro posicionamiento disciplinar, atento a que serán transferidos al ámbito de la formación, al convertirse en objeto de enseñanza.

Las disciplinas de diseño comparten comunes denominadores que las abarcan y a su vez se definen con las particularidades propias de cada una de ellas, que las diferencian.

Cada disciplina determina los límites y las reglas de su campo.

El campo es como un juego, pero que no ha sido inventado por nadie, que ha emergido poco a poco, de manera muy lenta. Ese desarrollo histórico se acompaña de una acumulación de saberes, de saber-hacer, de técnicas, de procedimientos, lo que lo hacen relativamente irreversible. Hay una acumulación colectiva de recursos colectivamente poseídos, siendo una de las funciones de la institución escolar en todos los campos y en el campo del arte en particular, dar acceso (desigualmente) a esos recursos. (Bourdieu, 2003 p. 38) 
"El campo es escenario de relaciones de fuerza y de luchas encaminadas a transformarlas y, por consiguiente, el sitio de un cambio permanente" (Bourdieu, 1995, p. 69). Cabe agregar que buena parte de este cambio se gesta en las aulas.

Por otra parte, cada asignatura tiene sus propias características que las definen.

Las aquí tratadas aluden a las materias proyectuales de las carreras de arquitectura y diseño, las que comparten importantes aspectos que las relacionan: su poder de estructuración de lo social, su raíz proyectual caracterizada por la transformación, el modo de pensamiento y conocimiento, las maneras de internalizar la práctica, el trabajo en taller y las modalidades de corrección, todos ellos elementos comunes que definen un campo en el cual la imagen ocupa un lugar central.

En las sucesivas inclusiones que definen las decisiones en el ámbito de la formación, a su vez sometido a otras influencias que le son ajenas, la más general corresponde a las políticas educativas, como parte de las políticas públicas, las que a nivel nacional, provincial y local determinan la oferta académica, su financiación, las prioridades, el sistema de ingreso, las condiciones de permanencia y egreso y todas las decisiones que en un nivel macro regulan el sistema dentro del cual cada unidad académica habrá de darse su propia organización, definiendo el perfil profesional a lograr de acuerdo a objetivos predeterminados, administrando el presupuesto y tomando las decisiones académicas de acuerdo a sus particulares y múltiples intereses.

En esta instancia institucional la oferta quedará regulada por la currícula de cada carrera y asignatura acorde al recorte de cada institución, así, en los distintos niveles de la programación de la enseñanza, volveremos a encontrar esta múltiple organización inclusiva que fue asemejada a la imagen de la matrioska.

En el caso de la Facultad de Arquitectura, Diseño y Urbanismo de la Universidad de Buenos Aires, al ser una universidad pública y masiva, se determinan de un modo muy amplio los objetivos y contenidos mínimos de los cursos de cada asignatura, que luego son redefinidos en un ámbito de libertad de cátedra por cada uno de los profesores que dictan la materia, respetando esta programación general y abriendo un abanico de alternativas caracterizadas por el sello de la diversidad.

Este esquema es similar en otras universidades de matrícula numerosa y va reduciendo su nivel de complejidad en las facultades públicas o privadas de menor escala, que disponen de una menor variedad de opciones permitiendo, a cambio, una mayor coherencia decisional. Ya próximos a la instancia que nos interesa como eje de este desarrollo, aquella donde los matices ideológicos pasan a ser determinados por la cosmovisión de cada uno de los profesores titulares, que como se anticipó no pueden ser totalmente independientes de las instituciones que los incluyen como tampoco lo son estas de los otros niveles de generalidad que las abarcan, reiterando que los mismos conservan un amplio margen de decisión para diseñar el perfil de cátedra y, en esa franja decisional, se juegan las distintas alternativas que constituyen la variedad de ofertas académicas ofrecidas.

Otros actores intervinientes, docentes y estudiantes, a su vez aportan sus propias cosmovisiones que, en relación y tensión dialéctica, se influyen mutuamente construyendo las miradas que van a reflejarse sobre el proyecto. 
Los saberes disciplinares, en continuo cambio debido al juego de las múltiples influencias que los incluyen, han determinado a lo largo de la constitución y consolidación de cada disciplina una serie de etapas variopintas que dejaron su sello en los modos de concebir en cada oportunidad los perfiles profesionales.

A menudo ignoramos o no percibimos los nudos que sujetan y articulan la propia especialidad técnica a las relaciones de poder y sus transformaciones, con frecuencia no podemos percibir las razones por las cuales una propuesta que se imagina técnicamente correcta no halla espacio para su realización. (Ciriza en Cirvini, 2004 p. 13)

La etapa fundacional de la arquitectura, muy ligada a la ingeniería marca una sucesión de acciones posteriores acompañadas por cambios en los perfiles disciplinares y adecuaciones a diferentes contextos, ante la necesidad de demarcación, diferenciación y definición del campo.

Oportunamente la constitución de cada disciplinas de diseño, tuvo la misma lucha por su diferenciación.

En la Facultad de Arquitectura Diseño y Urbanismo de la UBA por ejemplo, las distintas carreras de nacieron dentro de la entonces llamada FAU (Facultad de Arquitectura), tomaron muchas de sus modalidades de estructuración y compartieron buena parte de su plantel docente, librando su propia batalla por tratar de definir cada una de ellas- su propio perfil académico.

Silvia A. Cirvini, en su libro Nosotros los Arquitectos hace un minucioso análisis de las distintas etapas de constitución y consolidación por las cuales fue pasando la disciplina y tomando a Pierre Bourdieu como clave de lectura, analiza el proceso de diferenciación inicial y dice que:

Los habitus son principios generadores de prácticas distintas y distintivas pero también son esquemas clasificatorios, principios de clasificación, principios de visión y de división, aficiones diferentes. Establecen diferencias entre lo que es bueno y lo que es malo, entre lo que está bien y lo que está mal, entre lo que es distinguido y lo que es vulgar, etc., pero no son las mismas diferencias para unos y otros. (Cirvini, 2004, p. 279)

En otro orden de cosas, las fuentes que sustentan el saber disciplinar de la arquitectura y de cada disciplina de diseño, también emergen del campo de la teoría, del ámbito de la investigación y de los proyectos y productos, que se instauran como referentes teóricos y antecedentes destinados a nutrir las nuevas producciones. Todos ellos son intencionalmente elegidos en el contexto de las cátedras, acompañados por el sesgo ideológico que se desea transferir a la enseñanza.

En tanto ningún hacer se explica desde el hacer mismo, la teoría se anticipa como saber fundamentador, ésta puede interpretarse como la ciencia del sentido, una abstracción ordenadora que convierte lo real en cierta y específica realidad, determinada y determinante del contexto cultural con el cual interactúa. (Morales, 1999, pp. 135-141)

Así entendida la teoría de los talleres proyectuales también es preceptiva, en tanto es lo que el alumno deberá tener en cuenta anticipadamente para proyectar, la que nutrirá su interpretación y luego su creación, incluyendo la condición productiva por la que deviene en objeto. 
La investigación en el área de diseño y la construcción de teoría permanecen, en general, menos desarrollados que las producciones concretas del campo, si bien éstas también se constituyen en material de enseñanza y construyen teoría que, por ser tal, comporta el mismo carácter ideológico.

Las prácticas desarrolladas en los talleres tienen grandes similitudes con las desarrolladas en la práctica profesional, proponiendo a los estudiantes una suerte de simulacro que les permite apropiarse de las lógicas disciplinares. Pero esta práctica hace otro aporte a la disciplina, ya que a diferencia de lo que sucede en otras, gran parte de la teoría del diseño se formula en su enseñanza. (Mazzeo, 2014, p. 20)

El material elaborado para la enseñanza y los referentes de la práctica que se utilizan como fuente de conocimiento, elegidos en ejercicio de un pensamiento crítico e iluminados por estos fundamentos teóricos, implican un juicio y remiten a los valores que se ostentan y se desean trasmitir.

Responden, en síntesis, a una pregunta ontológica: "que hace el hombre al hacer arquitectura y qué hace del hombre la arquitectura". (Morales, 1999, p. 16)

Esta pregunta ontológica, por extensión aplicable al diseño, encuentra su respuesta final en el objeto diseñado y en la dialéctica de sus acciones y reacciones dentro del contexto del hábitat, habilitando gozosos encuentros o penosos desencuentros con el ser en plenitud, de cada potencial destinatario.

Cada uno de nosotros plantea su relación con el mundo y sus semejantes a partir de un esquema de concepciones previas elaborado a lo largo de la vida, a través de nuestras múltiples experiencias; un esquema conceptual referencial operativo, como lo llama Pichon Rivière, una grilla dinámica que tamiza todos nuestros conocimientos y acciones. Sobre este esquema, que incluye las concepciones disciplinares, se implementan nuestras acciones y se monta todo nuevo conocimiento.

El recorte del conocimiento disciplinar, sesgado por la cosmovisión de cada profesor a cargo de una cátedra, es el punto de partida para diseñar el objeto de enseñanza de cada disciplina. Es el primer gesto decisional del titular que dicta la asignatura, sea esta elección totalmente consciente o devenida intuitivamente de los conocimientos del campo que haya naturalizado en su ejercicio profesional y académico, lo explicite o no ideológicamente. En el material que elabora para la enseñanza, refleja como una presencia tácita sus concepciones, las que luego serán transferidas a su hacer, definiendo un determinado perfil de cátedra a trasmitir a su equipo docente y alumnos.

Al proyectar el saber a enseñar, todas estas elecciones, que derivan de su puesta en acción en la didáctica disciplinar, asumen para bien o para mal la respuesta a aquella pregunta ontológica, su trascendencia y su calidad de trasmisión a los estudiantes, que ya graduados lo trasladarán en alguna medida a su ejercicio profesional, con la correspondiente incidencia en sus contextos de influencia.

La construcción del saber a enseñar

La construcción del saber a enseñar tiene fuerte vínculo con el saber disciplinar que le da origen y es el titular de la materia, como jefe de cátedra, quien tiene a su cargo el diseño del objeto de enseñanza de acuerdo con su filosofía y sus concepciones profesionales. 
Los instrumentos didácticos producidos reflejan, explícitamente o entre líneas, sus concepciones acerca de la enseñanza y su aproximación al perfil profesional deseado.

El saber a enseñar debe sufrir, para su implementación, la trasposición didáctica necesaria para hacerla accesible a los alumnos, la cual debe ser mantenida bajo una constante vigilancia epistemológica para que no pierda su vínculo genuino con el saber disciplinar y con su actualización. (Chevallard, 2005, p. 45)

Los marcos disciplinares, hoy mucho más abiertos e interrelacionados, con límites más difusos, configuran un recorte permeable en constante transformación, que amerita ser reconsiderado continuamente para mantener al día el saber a enseñar.

La ética personal y profesional de cada profesor marca, inevitablemente, estas cadena de decisiones constantes y dinámicas. Los instrumentos producidos para su implementación en la enseñanza, que reflejan las concepciones teóricas e ideológicas del titular de la cátedra, son el bagaje que luego recibe cada docente del equipo para transmitirlo en acciones a su grupo de alumnos, realizando su propia interpretación y recorte, de acuerdo a su personal esquema conceptual operativo. De la coherencia interna del equipo que integra cada taller de diseño dependerá la mayor o menor fidelidad a la propuesta del titular a cargo y, sería deseable, que esta cosmovisión de la disciplina fuera trasmitida y discutida con los alumnos para sellar un contrato didáctico tácito pero transparente con la cátedra que ha elegido para definir buena parte de su futuro perfil profesional.

Sin ánimo de profundizar en la producción de los instrumentos didácticos, el mismo refleja la ideología subyacente en cada una de las elecciones, comenzando por los objetivos y contenidos que se haya decidido implementar; el material teórico que se elabore, el tema planteado para su desarrollo y la manera en que se enuncie; el enfoque que se proponga; el nivel de relaciones contextuales que se establezca; el grado de compromiso con la cultura y la sociedad a las que sirve; la bibliografía general y particular que se elija; los referentes que se utilicen como ejemplos; la metodología que se implemente; los problemas que se enfoquen; los tiempos asignados en el cronograma a cada uno de los requerimientos a resolver; son todos ellos, desde su sólo enunciado, el detonante de una sucesión de decisiones encadenadas, que requieren planificación y coherencia.

Estos instrumentos didácticos sugieren también el nivel más general de las estrategias que motivan el aprendizaje, adecuándolas a los distintos momentos formativos y delineando el vínculo entre el alumno y el docente, si bien le cabe a este último reconocer y solucionar con lucidez cada problema apelando a los recursos que en cada caso estime convenientes, diseñando sus propios métodos de enseñanza derivados en acciones flexibles y situadas que tienen por destino facilitar al estudiante la apropiación del conocimiento. Estas acciones dependen de las características de éstos y de cada proyecto, que actúa como intermediario en la articulación de la enseñanza y el aprendizaje.

\section{La construcción del saber enseñado}

En este proceso llegamos al lugar del docente -principal actor del saber enseñado- que, en su función formativa, es el encargado directo de articular con el alumno una parte sustancial de la relación entre la enseñanza y el aprendizaje y que dejará progresivamente su impronta personal sobre el. 
Cabe aclarar que esta relación es asimétrica, en tanto la enseñanza y el aprendizaje definen roles, intereses y funciones de características claramente diferenciadas.

En esta relación intersubjetiva, en tensión dialéctica constante, hay una energía común que es impulsada por el vínculo y les permite progresar conjuntamente.

Nuevas concepciones se articularán y nuevas concepciones se modelarán en el proceso.

El docente concreta su contacto con la disciplina con su bagaje de vivencias, su forma de ver el mundo, la matriz a partir de la cual incorpora nuevos conocimientos, que se amalgaman con sus experiencias previas.

En su actividad como educador implementa los saberes provenientes de su educación, su experiencia disciplinar y profesional, integrados con los saberes propios de la enseñanza, más o menos formalizados en conocimientos didácticos según los casos, sean adquiridos desde la formación docente, sean desde una construcción empírica, sean desde los modelos docentes de los que ha aprendido y desde la capitalización de sus propias experiencias. Vygotsky sugiere que el docente no puede ir más allá de crear las circunstancias y condiciones más propicias para que tenga lugar el aprendizaje, en tanto es el estudiante el que aprende de sus propias actividades, educándose a sí mismo.

Esta circunstancia, lo coloca en el lugar de disponer y coordinar las circunstancias para que el aprendizaje pueda producirse, lo cual requiere formación, experiencia, perfeccionamiento y capacitación para crear el ambiente propicio; para generar estrategias didácticas y llevarlas a cabo; para reflexionar sobre el propio hacer y afianzar su desempeño; para coordinar y compatibilizar con su cátedra y colegas un equipo de trabajo integrado, aportando su propia interpretación de las consignas y de todo el material recibido para que implemente el objeto de enseñanza de su taller.

Este proceso suele ir naturalizando una cosmovisión que inconscientemente oculta acríticamente sus orígenes mientras se sigue reproduciendo.

Desde estos lugares, en los que ha construido su imaginario, el docente expresa su ideología, trasmite su manera de entender el mundo, su cultura, su sociedad, su disciplina y la enseñanza, en tanto en cada gesto deja su impronta en el aprendizaje, desde donde el alumno la recibe, internaliza, replica y multiplica en sucesivas espirales de crecimiento cognitivo.

La apropiación del aprendizaje

El saber proyectual tiene la característica paradojal de conformarse en el marco del propio hacer, los mecanismos de apropiación del conocimiento se generan a partir de la acción proyectual individual, de la interrelación con el grupo de pares, del aporte del docente y de los instrumentos didácticos y teóricos preparados por la cátedra.

A su vez, cada estudiante posee sus propios esquemas para obrar, pensar y sentir, lo que Bourdieu llama habitus 
Son también el producto de condiciones sociales, históricas, etcétera y que tienen disposiciones, es decir, maneras de ser permanentes, la mirada, categorías de percepción, esquemas, estructuras de invención, modos de pensamiento, que están ligados a sus trayectorias: a su origen social, a sus trayectorias escolares, a los tipos de escuela por la que ha pasado. (Bourdieu, 2003, p. 40)

Ese saber empírico que el alumno trae consigo procede del conocimiento que tiene del hábitat, es adquirido en su acción cotidiana e influenciado por el contexto sociocultural al que pertenece. Esta experiencia de vida se manifiesta en sus acciones espontáneamente, hasta que las circunstancias demandan someterlas al pensamiento crítico.

Como parte de este bagaje están sus concepciones sobre los objetos de diseño, una mirada a menudo equívoca aplicada a multiplicidad de situaciones ajenas a la disciplina o modelada por los intereses del mercado, los emprendimientos inmobiliarios, la identificación con situaciones de prestigio socioeconómico, muchas veces ajenas a los contextos culturales donde se insertan, todo lo cual deberá someter trabajosamente a revisión para incorporar los referentes genuinos de su campo, lo que tendrá lugar durante su formación. Para mejor comprensión de estas transformaciones es oportuno profundizar el concepto acuñado por Pichon Rivière bajo el nombre de E.C.R.O. -esquema conceptual, referencial, operativo- que alude, como ya vimos, a los cambios que sufren las concepciones personales en los procesos de interacción con los otros.

Para el autor el aprendizaje está estrechamente relacionado con la noción de vínculo, entablada con el objeto de conocimiento mediante la acción. Este vínculo es siempre social y durante el aprendizaje se manifiesta en un proceso de sentir, pensar y hacer, simultáneos e interrelacionados con la acción de conocer.

El esquema conceptual es referencial, por ser la referencia para comprender la realidad, el campo sobre el cual va a operar y el conjunto de conocimientos presentes en el mismo y es operativo, por constituirse en la interacción con ese objeto de conocimiento que pretende aprehender; la operatividad supone la posibilidad de acción y cambio sobre un sector de la realidad.

El ámbito fundante del E.C.R.O. es la familia y a partir de ella cada individuo desarrolla matrices de aprendizaje que organizan su experiencia y universo de conocimiento, constituyen su subjetividad y su relación con el mundo.

Estas matrices funcionan como marco de referencia precedente, y en el trabajo grupal cada uno confronta sus modelos, elabora nuevas significaciones y aprende a partir del vínculo.

El sujeto que aprende se desestructura frente al nuevo conocimiento y debe volver a estructurarse, un movimiento dialéctico entre el mundo externo y su mundo interno.

Organiza e interpreta a partir del propio modelo conceptual internalizado y, en el grupo va modificando sus esquemas previos y los reconfigura.

El aprendizaje actúa como una apropiación instrumental de la realidad para transformarla y, en ese proceso, los actores se van transformado y modificando viejas estructuras por nuevas. 
Dependerá de las características individuales y de la flexibilidad para atravesar estas circunstancias, la manera en cómo se ponga en marcha para cada uno la espiral dialéctica del conocimiento. (Ritterstein, 2008)

En síntesis, en la relación de intercambio grupal y con el docente están presentes estos distintos esquemas conceptuales, referenciales y operativos, todo bajo el paraguas del E.C.R.O. propio de la cátedra, que propone los lineamientos en cuyo marco se desarrolla la formación.

Cada nuevo profesional, traduce estos esquemas de su formación a sus productos de diseño, los carga de significado y define su modalidad de interacción con el hábitat, al cual condiciona y siendo a su vez condicionado.

\section{El proyecto como mediador}

Enunciados algunos aspectos referidos a la construcción de las concepciones y representaciones en los actores comprometidos con la enseñanza y el aprendizaje del proyecto, se hace necesario caracterizar el mismo para comprender algunas de las mutuas influencias y transferencias ideológicas implicadas en el hacer proyectual cuyos resultados -consciente o inconscientemente- se reflejan en la producción de sentido de los objetos diseñados, independientemente de la disciplina. Bachelard dice que entre el sujeto y el objeto está el proyecto, esta mediación puede entenderse desde distintos enfoques: como proceso de generación, como tipo de conocimiento, como objeto de conocimiento, como productor de objetos o bien analizarlo en el proceso formativo, en la trama de intercambios dentro de la cual se produce su enseñanza y su aprendizaje.

La arquitectura y el diseño emergen como posibilidad a través de su pensamiento configurador, el proyecto, que implica y trasmite concepciones teóricas.

En un alto grado de generalidad puede definírselo en su episteme básico: es posible hacer "algo" que cambie "algo" actual en un "algo" deseado. (Iglesia, 2010, p. 96)

Se trata de un pensamiento aplicado "a la innovación, transformación y ajuste del hábitat existente"; coordenadas que delimitan un vasto espacio que incluye los saberes sobre el há- bitat humano (ambientales, sociales, culturales, tecnológicos, económicos, geopolíticos) y los saberes del campo específico, los que el estudiante recibe en su formación para aplicar más tarde a la producción de objetos y territorios. (Fernández, 2011, p. 257)

Es un modo particular de aprendizaje a través de la reflexión en acción, proceso que se desarrolla de manera paradojal ya que: la construcción progresiva del pensamiento proyectual demanda las habilidades del pensamiento proyectual.

Este aprendizaje se realiza en permanente intercambio con el docente mediante la elaboración conjunta del proyecto, en una constante relación intersubjetiva mediada por este, todo esto acompañado por los fundamentos teóricos que le permiten apropiarse del conocimiento disciplinar, adquiriendo paralelamente las habilidades proyectuales.

No hay una sola manera de proyectar y cada una tiene su propia modalidad operativa, sus propias teorías, su particular balance entre lo intuitivo y lo racional, su diversa consideración de las variables incidentes, sus 
correspondientes resultados y es en el marco de la cátedra donde se instauran estas concepciones.

Doberti alude a que "El proceso de diseño tienen una lógica específica que, sin embargo, se ve influida por otras lógicas que atraviesan el proceso y que lo anteceden y lo trascienden, tanto temporal como conceptualmente". (2008, pp. 214-224)

Estas lógicas, para integrar el proceso y considerar sus contextos, han atravesado previamente al diseñador, orientado su mirada y conducido sus decisiones.

Es en la lógica contextual "donde se establece la naturaleza de la producción arquitectó- nica, lo que implica la determinación esencial del sentido -o razón de ser- de todos sus elementos y principios de constitución". (Ibídem.)

Si bien el autor se refiere a la arquitectura esto es extensivo a la generación de todos los objetos del hábitat.

Menciona, asimismo, la lógica del espacio, que se aborda desde el hacer y el pensar, lugar de desarrollo de lo racional y lo sensible, que se configura en sus planos general-abstracto y contextual-sensible, definido como ámbito donde se desarrolla la vida humana, que requiere interpretación para acordarle sentido.

Incluye la lógica de la producción, que es específica de la elaboración de objetos y requiere tanto un saber y operar técnico como el reconocimiento del contexto socio-económico, en tanto vincula las posibilidades tecnológicas con la producción y la distribución espacial, los objetos y las imágenes.

Por último se refiere a la lógica de la función, orientada socialmente, que organiza el habitar y la comunicación y demanda de un pensamiento crítico para alentar las transformaciones legítimas.

Respecto a la lógica interna, no es otra que el proceso proyectual, un proceso complejo y recursivo, que atraviesa distintas etapas y grados de generalidad y en el que participan el bagaje de percepciones que el autor a atesorado a lo largo de su vida, las concepciones que haya construido y las representaciones elaboradas, que terminan conformado el objeto diseñado en un proceso proyectual que se caracteriza por la reflexión en acción, que tiene la capacidad de producir nuevos conocimiento en el diseñador y que, en la experiencia acumulada, conserva la posibilidad de iluminar otras prácticas.

Resulta redundante insistir en la carga ideológica que implica esta cadena decisional.

A su vez, durante el proceso de diseño los modelos de representación -que siempre expresan la visualidad de una cultura- condicionan el futuro objeto, delimitan, como todo lenguaje, el campo de lo posible, confieren características y valores al futuro objeto, revelan intenciones, tienen a su cargo la traducción de las imágenes mentales y sobre todo permiten desplegar la cadena de transformaciones sucesivas que termina concretándose en un objeto y construyendo las futuras relaciones con el hábitat.

De esta rápida e incompleta síntesis quizás pueda vislumbrarse la cantidad de influencias, presiones y cosmovisiones que se van movilizando, cruzando y transformando, desde que surge la necesidad a resolver, es interpretada por quien toma a su cargo la solución y atraviesa el proceso proyectual hasta que se convierte en 
proyecto, concreta las distintas circunstancias de su producción y se materializa en objeto, para concretar finalmente su dinámica relación dialéctica con el hábitat.

Esto nos lleva a inferir la importancia de la educación para instalar conductas adecuadas y evaluar la gravedad de establecer una perspectiva equivocada o una cosmovisión marcada por la falsa conciencia, para usar el término marxista.

El pensamiento de diseño

La formación profesional se enfrenta hoy a nuevos desafíos, confronta multiplicidad de referencias disciplinares en un medio cultural cuantitativa y cualitativamente en transformación, de complejidad y diversidad crecientes donde el conocimiento entra en rápida obsolescencia.

Estas circunstancias ameritan que las formas convencionales e intuitivas de trasmisión de las prácticas proyectuales sean analizadas y nutridas con nuevos aportes y, paralelamente, den lugar a una mayor profesionalización de la docencia para colocarla a la altura de esta renovación.

En los momentos de crisis, cuando la estabilidad estalla en pedazos, ya sea debido a las fluctuaciones internas, como por la aparición de cuestionamientos o demandas externas que afectan la práctica habitual, las creencias sobre el avance rectilíneo del conocimiento hasta cercar a la "verdad" se desvanecen. Las instituciones ven cuestionada la disciplina, en los dos sentidos antes mencionados. $Y$ es en ese momento en que suele aparecer el debate o la cuestión de la interdisciplina, e incluso de la transdisciplina. (Najmanovich, 2010)

Resumiendo, las concepciones personales que el diseñador trasmite al diseño devienen de una matriz que organiza su experiencia y universo de conocimiento, constituyen su subjetividad y su relación con el mundo, se originan en sus percepciones, devenidas concepciones, concebidas en sus ámbitos de procedencia, familia, sociedad, formación, actividad profesional y se convierten en la materia prima de sus representaciones.

En el momento de diseñar, el discurso social del hábitat lo atraviesa y se funde con sus propias vivencias; las circunstancias externas se articulan con las dos vertientes internas, racionalidad y poética, pensamiento sistemático e intuición, manifestadas en procesos conscientes e inconscientes que tienen lugar durante la reflexión en acción devenida en proyecto.

Estas vertiente aluden a categorías que se fusionan holísticamente, aunque a los efectos de su análisis es inevitable iluminar una y otra alternativamente para su comprensión.

El concepto generador del proyecto simboliza esa interpretación racional y sensible que da solución a la necesidad primaria y la trasciende cargándola de sentido y emoción y se expresa en unidad, a través de la forma devenida en vehículo comunicacional.

Del pensamiento crítico y la sensibilidad del diseñador para interpretar el discurso de la cultura, potenciarlo y expresarlo en soluciones pertinentes dentro de las reglas de su campo disciplinar depende la calidad de la respuesta a aquella pregunta ontológica planteada inicialmente. 
La formación ejerce una profunda influencia en la construcción de ese pensamiento y es posible nutrir las vertientes que consciente o inconscientemente se trasladan al proyecto y por ende al objeto, capitalizando durante el proceso de enseñanza los conocimientos tradicionales y enriqueciéndolos con los aportes de las nuevas teorías cognitivas capaces de completarlos y complementarlos, en tanto en el pensamiento proyectual se combinan distintos tipos de pensamiento funcionales al diseño que se nutren -o no- durante el aprendizaje. Por una parte, los conocimientos reconocidos, como la metodología de diseño y la concepción de sistema, actualmente casi olvidados, podrían retomarse, reconsiderando o subsanando aquellos aspectos que los hicieron caer en desuso y con ellos aportar al pensamiento crítico.

Por otra parte, las nuevas teorías cognitivas introducen nuevas visiones que pueden articularse con las tradicionales, el pensamiento complejo, las conversiones entre el conocimiento tácito y explícito, la teoría de las inteligencias múltiples, los aprendizajes en la acción, el pensamiento narrativo, etc. todos ellos posibles enfoques que pueden nutrir el pensamiento de diseño con miradas ampliadas, transversales e integradoras, conceptualizaciones que también pueden aportar a lo que se ha llamado 'caja negra' a la hora de proyectar, expresión con la que se metaforiza aquello de inefable que tiene el proyecto, lugares desde donde, el conocimiento sensible del proyectista, su intuición, su capacidad de metaforizar y producir asociaciones creativas en su área de conocimiento, pueden ser realimentadas. (Romano, 2015, pp. 45-64)

La capacidad racional, como aporte a un pensamiento proyectual crítico y el pensamiento poético, como motor de las emociones que trasmite, pueden potenciarse durante la formación, si se lo propone como objetivo de enseñanza y se diseñan los contenidos capaces de aportar a su construcción, incorporándolos explícitamente al taller e incluyéndolos en las líneas de investigación proyectual que los realimentan.

Cada decisión a tomar, el modo en que se implementa, cada acento a enfatizar, implica una decisión ideológica que resultará condensada en los instrumentos didácticos, los que presentan un particular recorte de la teoría y una mirada intencionada sobre la disciplina con su correspondiente influencia sobre los estudiantes.

Las metodologías significaron, oportunamente, una toma de conciencia de la magnitud de los problemas de diseño, acentuados con la revolución industrial, y los riesgos de encarar empíricamente su complejidad.

Este interés, que tiene su auge en la década de 1960 se proyecta hacia la actividad académica paralelamente con la Teoría General de los Sistemas, de Ludwing Von Bertalanffy, en momentos en que también la informática adquiría prestigio y difusión.

A partir de aquí y en relación con el diseño, la noción de sistema aportó desde dos lugares, como organizadora del proceso y como modo de concebir el objeto.

Estos conceptos condujeron la enseñanza del proyecto hasta que se fueron diluyendo tal vez por una excesiva esquematización en su uso, perdiéndose la oportunidad de actualizarlos para que siguieran contribuyendo a la enseñanza y a la práctica disciplinar.

Esa actualización hoy incluye las tecnologías digitales que abren un campo ilimitado a la investigación y producción del diseño, si bien en su vertiginoso progreso aún no han sido debidamente asimilados al campo de la enseñanza. 
Una década después, alrededor de 1970, surgen las corrientes sobre creatividad, con técnicas como las tormentas de ideas y las teorías del desarrollo del pensamiento lateral con Edward De Bono, entre otros.

Al mismo tiempo, J. Christopher Jones articulaba los conceptos de caja negra y caja de cristal y Christopher Alexander reconocía que los métodos de diseño, en su rigurosa racionalidad, no respetaban la estructura mental propia del diseñador. Así comienza a admitirse que no hay un método único y universal para alcanzar un objetivo y se valoran distintos puntos de vista, aceptando que la creatividad no implica una improvisación carente de método sino que ambos parámetros pueden articularse con éxito. En este punto de su evolución la metodología estaba en condiciones de aportar a las disciplinas y a la enseñanza del diseño, incorporando sus características particulares.

Es importante destacar que por esos años Edgard Morin comenzaba a desarrollar su teoría sobre la complejidad, describiendo el pensamiento complejo como un pensamiento capaz de negociar con lo real, que aparece allí donde el pensamiento simplificador falla, siendo su característica la multidireccionalidad y la integración, admitiendo la incertidumbre y siendo capaz de integrar y organizar.

Estas características de la complejidad son también propias del pensamiento proyectual. En la búsqueda de aportes para la generación de nuevos conocimientos actualmente se intentan caminos que retoman parte de lo recorrido; en la universidad de Stanford, por mencionar solo un ejemplo, se desarrolla un curso de posgrado y doctorado sobre las técnicas del desing thinking, definido como un enfoque que utiliza la sensibilidad del diseñador y sus métodos de resolución de problemas, una innovación centrada en la persona que se concentra en el proceso de diseño, integra conocimientos, forma equipos multidisciplinares y participa de proyectos de diseño, patrocinado por empresas.

A partir de recuperar y actualizar conocimientos, la metodología de diseño y el concepto de sistema podría revalorizarse en su capacidad de desarrollar alternativas de exploración del proceso proyectual, incluyendo la complejidad y enfatizando el valor de las técnicas que aportan al desarrollo de la creatividad, ampliando las experiencias de taller y los temas a investigar, revirtiéndolos en la formación del diseñador, planteando la posibilidad de desarrollar procesos reflexivos profundos que se abran a un pensamiento integrador, más lúcido e inclusivo que, iluminado por una conciencia sensible y ampliada, sea funcional al diseño como práctica social, donde también actúe desde la inclusión y la aceptación de la diversidad.

Cada toma de conciencia es un crecimiento de la conciencia, un aumento de luz, un refuerzo de la coherencia psíquica, dice Gastón Bachelar (1998, pp. 3-6) y agrega que en las horas de los grandes hallazgos, una imagen poética puede ser el germen de un mundo, el germen de un universo imaginado, “....en el resplandor de una imagen, resuenan los ecos de un pasado lejano, sin que se vea hasta que profundidad van a repercutir y extinguirse". (Bachelard, 1990 p. 8)

Un estudiante estará más preparado para analizar con lucidez el problema a resolver y producir evocaciones más potentes al plantear sus soluciones, si se cultivan y potencian sus capacidades en el contexto de la educación.

El taller puede generar nuevas experiencias, ampliar las fronteras del conocimiento racional y sensible, favoreciendo las situaciones capaces de germinar nuevos y conscientes procesos creativos. 
Según Eliot Eisner (1998, p. 40-42) la capacidad de experimentar cualidades requiere algo más que su presencia. La experiencia depende de una actuación de la mente y para ser cualitativa requiere de formas cualitativas de indagación. Los juicios cualitativos dependen del conocimiento del campo, implica capacidad para ver y esto necesita ser formado. Para hacerlo es necesario trascender la especificidad académica abrevando en todas las áreas de la cultura y aumentar el capital cultural disponible en los estudiantes.

El alumno puede llegar con falencias formativas anteriores, aún así le cabe a la universidad, como instancia disciplinar que acredita títulos habilitantes, hacerse cargo de subsanarlo. Pierre Bourdie propone que las diferencias en los resultados que presentan alumnos de diferentes clases sociales tienen relación con la formación a la que haya podido acceder en su contexto familiar y no con diferencias en sus aptitudes naturales. "El capital cultural es un tener transformador en ser, una propiedad hecha cuerpo que se convierte en una parte integrante de la 'persona', un hábito. (...) este capital cultural presenta un más alto grado de encubrimiento que el capital económico..." (Bourdieu, 2016, pp. 1-5)

Si en el contexto de la educación no podemos develar lo encubierto y subsanar sino eliminar estas desigualdades, proponiéndonos acciones que contribuyan a elevar ese capital como apropiación simbólica, inevitablemente tendemos a perpetuar las condiciones de esa marginación formando un egresado limitado en los resultados de su futuro ejercicio profesional porque "Sin duda, en la lógica de la transmisión del capital cultural es donde reside el principio más poderoso de la eficacia ideológica de este tipo de capital". (Ibídem.) En cada una de las etapas que atraviesa el proyecto puede tenerse en consideración insistentemente y con continuidad los distintos aspectos que orientan la mirada.

El planteo inicial del tema a desarrollar, puede ser elegido con la intención de producir el conocimiento de los problemas y contextos sociales significativos de la disciplina y ser presentado cualitativamente a los efectos de desencadenar un pensamiento comprometido, enriquecido con los debates que se propongan al respecto dentro de los grupos de trabajo. Los proyectos tomados como ejemplos para un análisis previo y las referencias teóricas que se utilicen pueden entroncarse coherentemente con los mismos objetivos, así, paulatinamente se va instalando un modo de ver y proceder, agudizando el espíritu crítico y cultivando una mayor sensibilidad para reconocer las problemáticas que se necesitan internalizar.

Durante el desarrollo de las alternativas de solución en las correcciones del proyecto, los diálogos que tengan lugar y el trabajo grupal pueden dirigirse también a despertar progresivamente una conciencia sensible que oriente la búsqueda de las soluciones más adecuadas, el mejor uso de los recursos y la correcta integración al medio físico y cultural así como la utilización de formas afines a estos contextos.

La necesidad de un pensamiento complejo, no algorítmico, que enfrente e incluya la incertidumbre y la indeterminación contemplando la organización, propiedades características del pensamiento proyectual, demandan la participación de distintas vertientes del conocimiento, acompañado por la investigación que provea nuevos recursos en el marco de cada una de las disciplinas de diseño, conjugando los aportes de otras áreas de conocimiento y tomando continuas decisiones que requieren concepciones ideológicamente claras.

Los objetos y los contextos, portadores de sentido 
Hemos hablado de la concepción del objeto disciplinar trasmitida al objeto de enseñanza y finalmente al objeto diseñado que, como portador de sentido, entabla su relación dialéctica con el hábitat.

Allí se confrontan en tensión esos discursos concretando acuerdos y desacuerdos, encuentros y desencuentros, aportando vivencias a un espacio deshumanizado o humanizándolo en la dirección de su cultura y su historia.

El partido que se toma al enseñar se refleja en el partido que se toma al diseñar, decidiendo si las nuevas representaciones van a conformar un espacio trascendente, significativo, humanizado, o colmado de objetos vacuos que lo banalicen; si se pone al servicio de las necesidades de la sociedad o de alguna elite; si aporta a la construcción de la cultura, atendiendo su historia o la desdibuja, si genera trabajo genuino y resultados sustentables o agrava los problemas ya existentes, si las nuevas tecnologías de las que hoy dispone el diseño, tanto para su generación como para su producción, se ponen a disposición de soluciones superadoras para cubrir las necesidades crecientes o sucumben al magnetismo de seductoras morfologías, tan apreciadas por el mercado de bienes de consumo.

Este partido lo toma cada diseñador acorde a los contenidos, la capacidad reflexiva y el espíritu crítico que le haya aportado su formación y si bien “...no podemos saltar por encima de nuestro tiempo; estamos determinados por el espacio de los posibles ofrecido por el campo en un momento dado del tiempo y aprehendido a través de las lentes de un habitus". (Bourdie, 2010 p. 40)

Aún así, siempre hay intersticios por los que puede escurrirse la trasgresión, reinterpretarse los problemas y recrear las soluciones, y una parte importante del capital intelectual del diseñador, como vimos, se construye en los talleres de diseño, un desafío no menor en tanto: “... en el campo artístico, al igual que en el científico, es necesario tener mucho capital para ser revolucionario". (Bourdie, 2010, p. 30)

Las decisiones en la enseñanza pueden acompañar la formación de una conciencia responsable y un análisis lúcido de la realidad del cual emerjan soluciones creativas y socialmente comprometidas.

"Así, un proyecto, una nueva obra, no viene a confirmar el mundo tal cual es, sino que viene a hacer visible un nuevo mundo, actuando en el campo del sentido." y asumiendo la responsabilidad de que no se repita el estándar. (Lewkowicz, 2003, p. 55)

\section{Conclusiones}

Los objetos y contextos que forman hoy el entramado del hábitat humano están sometidos a todo tipo de presiones en una sociedad donde la fuerza del mercado determina los valores a consumir y moldean la mirada, que llega -alterada- a condicionar las demandas y, consecuentemente, las producciones profesionales y su enseñanza.

Será necesario deconstruir críticamente esa mirada para poder renovarla.

Las disciplinas del diseño, tan fuertemente enraizadas y comprometidas con las prácticas sociales y conscientes de la trascendencia de sus acciones sobre los futuros profesionales que participarán de esas prácticas, no debieran pecar de omisión en sus definiciones y, trasparentar los objetivos que vuelcan a la formación, permitiendo su conocimiento y aportando a los debates disciplinares acerca del perfil del diseñador que desean 
construir, investigando sobre las distintas vertientes capaces de nutrir el pensamiento y la sensibilidad proyectual.

Hace algunos años, en su libro Diseño Análisis y Teoría, la Dra. Marta Zátonyi escribía este párrafo cuya vigencia sigue intacta:

El diseñador puede participar en la formación del imaginario colectivo con valor y honestidad. No mostrar sólo aquello que la falsa conciencia de una sociedad, encarnada en sus individuos demanda, sino mostrar el otro lado de su realidad interior. Que no clama por las utopías, sino que busca una forma de vida creativa porque es su esencia, libre porque es consciente de sus derechos y deberes, generadora, inquieta, digna y solidaria. El diseñador es dueño de los medios para sugerir eso, así como para reforzar vicios y mentiras. (Zátonyi, 1993, p. 165)

Esa conciencia moldeada en gran parte por la formación debe estar intencionada hacia un fuerte humanismo que se replique en las acciones de diseño "(...) puesto que por definición el vínculo del sujeto humano con su realidad está mediatizado por las representaciones simbólicas, el consumo de representaciones es un insumo para la fabricación de los sujetos que corresponden a esas representaciones”. (Grüner, 2002, p. 360)

Como hemos visto durante este desarrollo, recorriendo las distintas instancias del conocimiento disciplinar y su enseñanza, el lugar donde estas representaciones se van modelando, donde se construyen los esquemas de referencia con los cuales pensamos y operamos sobre el mundo es durante la educación, con todas las influencias que hacia y desde ella emanan y si bien no podemos escapar a la marca de nuestro tiempo siempre habrá intersticios para poder operar si se ejerce una conciencia alerta.

Los temas propuestos, la forma en que se enuncia los ejercicios y la fundamentación teórica -ya sea que esta se manifieste explícitamente en las clases dadas por los docentes a cargo o estén implícitas en los otros elementos de la programación, como la bibliografía empleada, los referentes del campo profesional y los ejemplos utilizados como modelos referenciales- irán definiendo, para los estudiantes, el campo disciplinar. Ello es así porque el trabajo que se desarrolla en los talleres de diseño excede la sola práctica proyectual para constituirse en introductorio a las particularidades del campo mismo. (Mazzeo, 2014, p. 43)

La carga ideológica de estos instrumentos didácticos son los que operan -positiva o negativamente- sobre los futuros profesionales, aportan a la formación de su ética, enfocan su cosmovisión incorporando o desechando los discursos genuinos que emergen del contexto de su cultura y sobre los cuales puede aportar una mirada crítica para orientar soluciones eficientes y superadoras.

Por la sinergia del intercambio, aunque a largo plazo, la evolución que se produce en el interior de las cátedras va recorriendo el camino inverso y revierten su influencia a las instituciones y a la disciplina, modificando estructuras y orientando positivamente sus líneas evolutivas.

Para cerrar con la misma imagen inicial, la sucesión de aquella serie de muñequitas rusas -que abarcaba sucesivamente los contextos globales, nacionales, locales e institucionales- cuando transformamos la enseñanza el cambio empieza a producirse desde adentro hacia afuera, con la posibilidad de ir transformando 
diversas estructuras, si bien es innegable que el intercambio dialéctico es permanente, dinámico y se produce indistintamente en ambos sentidos.

\section{Referencias bibliográficas}

Bachelard, G. (1990). La poética del espacio. Buenos Aires: Fondo de Cultura Económica.

Bachelard, G. (1998). La poética de la ensoñación. Buenos Aires: F.de Cultura Económica.

Bourdieu, P. (1995). Respuestas - Por una antropología reflexiva. Argentina: Grijalbo.

Bourdieu, P. (2003). Creencia artística y Bienes simbólicos. Buenos Aires: Ed. A. Rivera.

Bourdieu, P. (2010). El sentido social del gusto. Buenos Aires: Siglo Veintiuno Editores.

Bourdieu, P. Los tres estados del capital cultural. Recuperado en agosto de 2016 de http:// sociologiac.net/biblio/Bourdieu-LosTresEstadosdelCapitalCultural.pdf

Chevallard, Y. (2009). La transposición didáctica. Buenos Aires: Editorial Aique.

Cirvini, S. A. (2004). Nosotros los arquitectos. Buenos Aires: Zeta Editores.

Doberti, R. (2008). Espacialidades. Buenos Aires: Ediciones Infinito.

Eisner, E. W. (1998). El ojo ilustrado. Buenos Aires: Editorial Paidós.

Fernández, R. (2011). Mundo diseñado. Santa Fe: Ediciones UNL. Recuperado en Marzo de 2012 de www.salvador.edu.ar/vrid/imae/a_lat-04

Gadner, H. (2001). Estructuras de la mente. Colombia: Fondo de Cultura Económica.

Grüner, E. (2002). El sitio de la mirada. Buenos Aires: Grupo Editorial Norma.

Iglesia, R. E. J. (2010). Habitar, Diseñar. Buenos Aires: Editorial Nobuko.

Lewkowicz I. Sztulwark P. (2003). Arquitectura plus de sentido. Buenos Aires: Ed. Altamira.

Mazzeo, C. (2014). ¿Que dice del diseño la enseñanza del diseño? Buenos Aires: Ed. Infinito.

Morales, J. R. (1999). Arquitectónica. Madrid: Editorial Biblioteca Nueva.

Najmanovich, D. (2010). Epistemología y nuevos paradigmas en educación. Educar y aprender en la sociedadred. Revista Rizona Freireano V6. Instituto P. Freire. España.

Najmanovich, D. (s.f.) Interdisciplina. Riesgos y beneficio del arte dialógico. Recuperado en julio 2016 de http://www.pensamientocomplejo.com.ar/docs/files/Interdisciplina\%20 -\%20Najmanovich.pdf 
Nussbaum, M. Recuperado en julio 2016 de https://redaccion.lamula.pe/2015/12/15/ martha-nussbaum-el-riesgode-una-educacion-basada-en-el-pbi-y-sin-humanidades/ rlescanomendez/

Pérez F. J. (et ál). (2002). Recorrido Histórico de la Metodología de Diseño. XIV Congreso Internacional de Ingeniería Gráfica. Santander. España.

Romano, A. M, (2015). Conocimiento y Práctica Proyectual. Buenos Aires: Ediciones Infinito.

Ritterstein, P. D. (2008). Aprendizaje y vínculo. Recuperado en agosto 2016 de www.catedras.fsoc.uba.ar/ferraros/BD/pr\%20aprendizaje\%20y\%20vinculo

Zátonyi, M. (2004). Diseño Análisis y Teoría. Buenos Aires: Edit. UP y Librería Técnica CP67.

Abstract:

The teaching of design, by the very characteristics of their doing, tends to keep tacit the arguments that support it, nevertheless, during the training they build in the students the approach on the discipline. This process, which is carried out in an institutional framework, is planned by the professorships that dictate the subject under the pedagogical proposal of each of the titular teachers, which will be finally interpreted and implemented by the teachers of his team, in direct link with the students. The students, on the other hand, come with their life histories and their background of previously acquired conceptions in their familiar and social context and their previous formation, from which they are going to incorporate the new knowledge, modifying these preexisting structures. The diversity of proposals and protagonists that converge in the framework of the teaching invite to reflect on the different instances that shape these conceptions of the students during the learning of design and that build their future professional profile and their cosmovision, while in the professional practice these conceptions are going to be transferred to the designed objects, directly influencing the users and the habitat with which they interact. The possibility of making this process transparent in each of the professorships could allow for the critical analysis and revision of the objectives and practices presented and to evaluate the consequences once implemented, in order to improve teaching, to increase knowledge of reality and increase social commitment.

Key words:

teaching - learning - cosmovision - project thinking - design.

Resumo:

O ensino do design, pelas suas caraterísticas, mantém tácitas as argumentações que a fundamentam, não obstante, durante a formação as mesmas vão construindo nos estudantes a mirada sobre a disciplina.

Este processo, realizado num marco institucional, é planejado pelas cátedras que ditam a matéria segundo a proposta pedagógica de cada um dos professores titulares, que será finalmente interpretada e implementada pelos professores do sua equipe, em vínculo direto com os estudantes. Os alunos, por sua parte, chegam com suas histórias de vida e seu cúmulo de conceições previamente adquiridos em seus contextos familiares, sociais 
e formações prévias, a partir das quais incorporarão novos conhecimentos, mudando essas estruturas preexistentes.

A diversidade de propostas e protagonistas que confluem no marco do ensino convida a refletir sobre as instancias que dão forma ás conceições dos estudantes durante a aprendizagem do design e que constroem seu futuro perfil profissional e sua cosmovisão, em tanto no exercício profissional essas conceições serão transferidas aos objetos desenhados, influindo diretamente sobre os usuários e o hábitat com que interatuam.

A possibilidade de transparentar este processo em cada uma das cátedras poderia permitir a análise crítico e a revisão dos objetivos e das práticas planteados e avaliar as consequências uma vez implementados, para melhorar o ensino, ampliar o conhecimento da realidade e aumentar o compromisso social.

Palavras chave: ensino - aprendizagem -cosmovisão - pensamento Projetual - design.

La construcción de la cosmovisión durante la enseñanza fue publicado de la página 215 a página234 en Cuadernos del Centro de Estudios de Diseño y Comunicación № 67 